\title{
Short Term Effects of a Pectoralis Minor Positional Release in Collegiate Swimmers: A Case Series
}

Jonathan Roman, MS, ATC and Noelle M Selkow, PhD, ATC

Illinois State University, Normal, IL

\section{ABSTRACT}

A tight pectoralis minor correlates to abnormal scapular kinematics, which can cause pain, loss of range of motion and even loss of function, due to the change in scapular position. With these muscular imbalances causing forward scapular posture, the pectoralis minor is a key component to address in the prevention and treatment of shoulder impingement and scapular dyskinesis. This study investigated the effectiveness of a single positional release therapy (PRT) treatment of the pectoralis minor on scapular posture in collegiate swimmers immediately and 24 hours post intervention. Seventeen Division III collegiate swimmers ( 7 males and 10 females) volunteered to participate, with only one shoulder being excluded due to recent injury $(n=33)$. Researchers measured resting pectoralis minor muscle length, forward shoulder posture and scapular elevation of both shoulders. Data were collected a total of 3 times; prior to the PRT intervention, right after the intervention and again 24 hours post intervention. Each shoulder was treated with a single session of PRT on the pectoralis minor. There was a significant difference for resting pectoralis minor length immediately post-intervention compared to baseline $(p=.016)$. Scapular positioning at $0^{\circ}$ abduction had a statistically significant improvement in position from immediate post-intervention to 24 hours postintervention $(p=.014)$. Scapular positioning at $90^{\circ}$ of abduction also had a statistically significant increase in position from baseline to immediate post-intervention $(p=.042)$. For forward shoulder posture, there was a statistically significant improvement in position from baseline to immediate post- intervention $(p \leq .001)$. The results of this case series show that a single treatment of PRT has an immediate effect in reducing resting pectoralis minor muscle length and decreasing rounded shoulder posture. However, this single treatment of PRT was not enough to maintain these effects after 24 hours, and should be combined with other manual therapies or rehabilitation protocols to address scapular positioning in collegiate swimmers.

\section{Key Phrases}

Manual techniques, injury risk reduction, college and university patient population

\section{Correspondence}

Dr. Noelle M Selkow, Illinois State University, School of Kinesiology and Recreation, Cmaous Box 5120, Normal, IL, 61761.

E-mail: nselkow@ilstu.edu

Twitter: @docselkow

\section{Full Citation}

Roman J, Selkow NM. Short Term Effects of a Pectoralis Minor Positional Release in Collegiate Swimmers: A Case Series. Clin Pract Athl Train. 2018;1(2):42-48. https://doi.org/10.31622/2018/0002.7

Submitted: August 29, 2018 Accepted: October 15, 2018

\section{INTRODUCTION}

There is a consistently growing population of collegiate swimmers within Division I, II, and III institutions totaling around 486,000 swimmers in the 2015-16 academic year. ' Competitive swimming athletes are at risk for shoulder injury due to an excessive amount of shoulder revolutions that can cause the anterior shoulder musculature to hypertrophy. ${ }^{2}$ During the freestyle, butterfly, and backstroke of competitive swimming, the athlete is consistently applying adduction and internal rotation forces from the shoulder in order to propel themselves through the water, which may lead to an imbalance of agonist-antagonist muscles. ${ }^{3}$ This muscular imbalance often leads to scapular dyskinesis, which is defined as abnormal movement patterns causing alteration of optimal scapular kinematics. 4,5

The pectoralis minor specifically has been related to shoulder pain in swimmers, ${ }^{2}$ and scapular dyskinesis due to its shortened muscle length.6,7 A tight pectoralis minor can be either a primary or secondary cause of shoulder pain, 8 and the diminished muscle length prohibits proper scapular upward rotation, posterior tilting and external rotation.9-11 Often times swimmers with bilaterally tight pectoralis minor muscles develop forward scapular posture, which has been described as a forward head and rounded shoulders position, and contributes to shoulder impingement. 2,9,12 Previous studies have stated that the pectoralis minor muscle tightness is typically due to adaptive changes in the muscle belly from repetitive motions that involve scapular 
protraction and anterior tilting and/or by maintaining a static shortened position over time. ${ }^{8,9}$ With these muscular imbalances causing forward scapular posture, the pectoralis minor is a key component to address in the prevention and treatment of shoulder impingement and scapular dyskinesis.9,11,13,14 Manual therapies such as stretching, ${ }^{13-15}$ Muscle Energy Technique (MET),16 and Myofascial Trigger Point ${ }^{17}$ have shown to be effective in treating shoulder impingement symptoms. Previous research articles have addressed the need for interventions that can increase the pectoralis minor resting length in shoulder rehabilitation protocols. $2,7,11,12$

Positional Release Therapy (PRT), under the umbrella of strain-counterstrain, 18 is similar to Myofascial Trigger Point. ${ }^{19}$ Strain-counterstrain addresses dysfunctional tissue by putting them in a slacked position to decrease activity from proprioceptors. ${ }^{20}$ However, PRT uses tender points and a position of comfort to resolve the associated dysfunction, instead of attempting to stretch the muscle. ${ }^{21,22}$ Unlike Myofascial Trigger Points that are hyperirritable bands of tissue, tender points are discrete areas of tissue tenderness that can occur anywhere in the body. ${ }^{21,22}$ PRT treatment begins by identifying a tender point, the clinician positioning the patient in a position of comfort that is typically obtained by shortening tissues around the tender point while a slight touch monitors the position. ${ }^{23,24}$ This position is then held for 90 seconds, and then slowly returning the patient to normal resting position. ${ }^{22,23}$ Although this technique has been around for many years, 25 and there has been some evidence of its clinical usefulness, ${ }^{26-28}$ further research on the effects of PRT are still needed. $21,22,29-31$

The purpose of this study was to investigate the effectiveness of a single PRT treatment of the pectoralis minor on scapular posture in collegiate swimmers immediately and 24 hours post intervention. The hypothesis is that the PRT intervention will lengthen the pectoralis minor, decrease the forward scapular position and increase scapular upward rotation in the group of collegiate swimmers.

Copyright ( $)$ by Indiana State University All rights reserved. ISSN Online 2577-8188

\section{METHODS}

\section{Design}

This design of this investigation was a case series, where the athletic trainer for the swim team performed all PRT treatments and measurement. The athletic trainer was certified for 1.5 years. The athletic trainer attended a PRT course for the upper extremity and was trained in the technique utilized in this study. All participants received the intervention on both shoulders, unless excluded. There was no true control group, as the athletic trainer and coach wanted all swimmers to receive a potentially beneficial treatment. Hence, this was a sample of convenience. The independent variables were intervention (PRT to the pectoralis minor) and time (baseline, immediately post intervention, and 24-hours post intervention). The dependent variables were pectoralis minor length $(\mathrm{cm})$, forward shoulder posture as measured with the double square $(\mathrm{cm})$, and scapular position in $0^{\circ}, 45^{\circ}$, and $90^{\circ}$ of shoulder abduction $(\mathrm{cm})$.

\section{Participants}

Participants included 17 Division III Collegiate swimming athletes ( 7 males and 10 females; Age: $20.0 \pm 1.4$ years; Height: $170.9 \pm 8.6 \mathrm{~cm}$; Mass: $69.3 \pm 12.8 \mathrm{Kg}$ ). Shoulders of swimmers that had a recent history (past 6 months) of upper extremity injury or any history of upper extremity surgery were excluded from the study Only one participants' shoulder was not measured due to recent injury $(n=33)$. All participants were in the post season at the time of data collection. Both left and right shoulders were used for data collection. The institutional review board at the university approved this study and all participants signed informed consent.

\section{Resting Pectoralis Minor Length Measurement}

Participants were instructed to lie supine with arms at their side in a relaxed position. The measurement landmarks were from the medial inferior angle of the coracoid process to the anterior-inferior edge of the $4^{\text {th }}$ rib, 1 finger width lateral to the sternum. ${ }^{32}$ Using the Pectoralis Minor Index (PMI), 9 each shoulder was measured in centimeters then divided by the participants 
height in centimeters and multiplied by 100 to account for limb height. (Figure 1)

\section{Forward Shoulder Posture Measurement}

After palpating the anterior tip of the acromion process on the participants shoulder, the location was marked on the participant's skin with a permanent marker. The participant was then instructed to move backwards towards the wall until their heels and back touched the wall. The examiner then positioned the double square instrument over the shoulder being examined. With one square flush against the wall, the other square adjusted until it touched the tip of the acromion process marked previously measured in centimeters $(\mathrm{cm}) \cdot{ }^{33}$ (Figure 2)

\section{Scapular Positioning}

We measured the participant's scapular mobility using the Lateral Scapular Slide Test (LSST). ${ }^{34}$ The examiner used a cloth measuring tape to determine the distance from the inferior angle of the scapula to the nearest spinous process in 3 different shoulder positions in centimeters $(\mathrm{cm})$. The first position was with their arms relaxed at their sides $\left(0^{\circ}\right.$ abduction). The second was with the participant's hands on their hips with their fingers on the anterior side and thumbs on the posterior side of their waist, with about $10^{\circ}$ of shoulder extension $\left(45^{\circ}\right.$ abduction). The third position is with their arms at $90^{\circ}$ of shoulder elevation with their thumbs pointed downward. (Figures 3-5)

\section{Positional Release Therapy for the Pectoralis Minor}

The participant was placed supine on the table. Using one hand to palpate for tender points, the examiners other hand grasped the forearm of the treatment side. Upon finding a tender point, the examiner monitored the palpation and began to move the treatment arm across the body towards the opposite hip, and then applied a distraction force with internal rotation to fine tune the position so that the fasciculation response was most prominant. ${ }^{22}$ The fasciculation response is a continuous small amplitude twitch, similar to a pulse, where the tender point is located and examiner's fingers are located. The position of comfort was painless and allowed the participant

Copyright (C) by Indiana State University All rights reserved. ISSN Online 2577-8188 to relax. The examiner held this position for 90 seconds (Figure 6) and then slowly returned the arm to neutral and re-evaluated the tender point. A successful treatment was determined by a decrease in pain on the tender point as indicated by the patient. The examiner repeated the procedure for all tender points located on the involved pectoralis minor muscle. No other interventions were used.

Procedures

Data measurements were collected a total of 3 times on each participant. They were measured prior to the PRT intervention, right after the intervention and again 24 hours post intervention. During the length of the study (24 hours), the participants were not to participate in any physical activity.

\section{Statistical Analysis}

Separate paired-samples t-test were conducted to evaluate the effect of PRT for the pectoralis minor on pectoralis minor length, scapular positioning, and forward shoulder posture. Cohen's d effect sizes were calculated for significant findings. Alpha was set a priori at $\alpha=0.05$. IBM SPSS Statistics 25 (Chicago, IL) was used for statistical analysis.

\section{RESULTS}

Means and standard deviations, along with $p$ values and effect sizes are presented in Table 1. The only significant finding with an effect size that did not cross zero was for forward shoulder posture. Forward shoulder poster decreased immediately after the PRT intervention, but the results were not maintained 24 hours postintervention.

\section{DISCUSSION}

Due to the nature of the sports, repetitive motions of the shoulder tend to cause muscular imbalances and can lead to injury. ${ }^{2,3}$ Because of this, clinicians and health care professionals utilize a variety of manual techniques to address the over active anterior muscles that may contribute to injury. 
Table 1. Means, SD, and p-values of Clinical Outcomes. Effect sizes for significant $p$-vales provided

\begin{tabular}{|c|c|c|c|c|c|c|}
\hline & Baseline & $\begin{array}{l}\text { Post- } \\
\text { Intervention }\end{array}$ & $\begin{array}{l}\text { Post- } \\
\text { Intervention } \\
\text { to Baseline } p \\
\text { value }\end{array}$ & $\begin{array}{l}24 \text { hrs Post- } \\
\text { Intervention }\end{array}$ & $\begin{array}{l}24 \text { hrs Post- } \\
\text { Intervention to } \\
\text { Post- } \\
\text { Intervention p } \\
\text { value }\end{array}$ & $\begin{array}{l}24 \text { hrs Post- } \\
\text { Intervention } \\
\text { to Post- } \\
\text { Intervention p } \\
\text { value }\end{array}$ \\
\hline \multicolumn{7}{|l|}{ Pectoarlis } \\
\hline $\begin{array}{l}\text { Minor } \\
\text { Length } \\
(\mathrm{cm}) \\
\text { Scapular }\end{array}$ & $18.02 \pm 1.14$ & $18.38 \pm 1.25$ & $\begin{array}{l}P=.016 \\
E S=.36 \\
(-.12-.85)\end{array}$ & $18.06 \pm 1.17$ & $\begin{array}{l}P=.016 \\
E S=.26 \\
(-.22-.75)\end{array}$ & $P=.813$ \\
\hline $\begin{array}{l}\text { Position } 0^{\circ} \\
(\mathrm{cm})\end{array}$ & $9.40 \pm 1.53$ & $9.47 \pm 1.67$ & $P=.701$ & $9.76 \pm 1.89$ & $\begin{array}{l}P=.014 \\
E S=.18 \\
(-.31-.66)\end{array}$ & $P=.098$ \\
\hline \multicolumn{7}{|l|}{ Scapular } \\
\hline $\begin{array}{l}\text { Position } \\
45^{\circ}(\mathrm{cm}) \\
\text { Scapular }\end{array}$ & $10.18 \pm 1.44$ & $10.18 \pm 1.48$ & $P=.955$ & $10.26 \pm 1.45$ & $P=.162$ & $P=.441$ \\
\hline $\begin{array}{l}\text { Position } \\
90^{\circ}(\mathrm{cm})\end{array}$ & $10.53 \pm 1.84$ & $10.23 \pm 1.71$ & $\begin{array}{l}P=.042 \\
E S=-.17 \\
(-.65-.32)\end{array}$ & $10.79 \pm 1.82$ & $\begin{array}{l}\mathrm{P} \leq .001 \\
\mathrm{ES}=.35 \\
(-.13-.84)\end{array}$ & $P=.172$ \\
\hline \multicolumn{7}{|l|}{ Forward } \\
\hline $\begin{array}{l}\text { Shoulder } \\
\text { Posture } \\
(\mathrm{cm})\end{array}$ & $15.81 \pm 1.55$ & $14.85 \pm 1.5$ & $\begin{array}{l}P \leq .001 \\
E S=-.67 \\
(-1.16- \\
-.17)\end{array}$ & $15.64 \pm 1.42$ & $\begin{array}{l}P \leq .001 \\
E S=-.54 \\
(-1.03- \\
-.05)\end{array}$ & $P=.379$ \\
\hline
\end{tabular}

Although PRT is becoming more popular among clinicians, there is no previous research using PRT on the pectoralis minor in swimmers. This case series has indicated that there is merit to PRT, when used to address the pectoralis minor in asymptomatic swimmers, to decrease rounded shoulders posture after a single treatment session.

A tight or shortened pectoralis minor has been correlated to abnormal scapular kinematics, causing the rounded shoulder posture observed in most swimming athletes. $2,6,12,15,16$ The increased anterior tilting, internal rotation and downward rotation of the scapula is partly due to the line of pull of the pectoralis minor, 9 along with other muscles, such as the pectoralis major and scapular retractors. ${ }^{35}$

From our findings, PRT seems to influence forward shoulder posture immediately after intervention to the pectoralis minor. Clinicians can utilize this technique during a rehabilitation session to help

Copyright ( $)$ by Indiana State University All rights reserved. ISSN Online 2577-8188 position the scapula in more neutral position before strengthening exercises are implemented.

Therefore, the muscles around the scapula will be strengthened in a more optimal position. Strengthening exercises alone may take as long as 8 weeks to correct scapular positioning. ${ }^{36}$ Compared to other manual therapy treatments, muscle energy technique has been shown to increase pectoralis minor length and decrease forward shoulder posture after a 6-week intervention, 16 although it is unknown what changes would occur after 1 session of muscle energy technique. With limited research on manual therapy for forward shoulder posture, PRT seems to be a good option when initially addressing this condition.

There were some limitations to this study that could attribute to the results that were found. The PRT treatment session was altered from the current treatment protocol of holding the position of comfort until fasciculation decreases significantly 
or ceases, to holding for a set time of 90 seconds, to help standardize the treatment for all participants in this study. ${ }^{21,22,31}$ Furthermore, when using PRT to treat injuries of the shoulder, such as shoulder impingement or scapular dyskinesis, multiple muscles need to be identified and treated over multiple sessions to correct the problem. ${ }^{22,31}$ Lastly, the single PRT session was done by a clinician with novice training, and not a full certified PRT clinician.

For future research studies a full PRT treatment involving multiple targeted muscles should be performed as outlined by Speicher. ${ }^{22}$ The treatment should be performed by a PRT certified clinician, and there needs to be more than one treatment session. Furthermore, more measurements should be taken, such as a visual analog pain rating scale, humeral abduction ROM and humeral horizontal abduction ROM. Also, future research should look into seeing if dominant arm and breathing side plays a role in ROM restrictions in each swimmer.

\section{CLINICAL APPLICATION}

This case series was used to identify if PRT was an effective treatment method to influence scapular posture in collegiate swimmers. The results of this case series show that a single treatment of PRT may have an immediate effect in reducing resting pectoralis minor muscle length and decreasing rounded shoulder posture. However, this single treatment of PRT was not enough to maintain these effects after 24 hours, and should be combined with other manual therapies or rehabilitation protocols to address scapular dyskinesis in collegiate swimmers.

\section{REFERENCES}

1. Irick E. NCAA Sports Sponsorship and Participation Rates Report 1981-82 - 201516. Indianapolis, IN: National Collegiate Athletic Association; 2016.

2. Kluemper $M$, Uhl $T$, Hazelrigg $H$. Effect of stretching and strengthening shoulder muscles on forward shoulder posture in competitive swimmers. J Sport Rehabil. 2006; 1 5(1):58-70. https://doi.org/10.1123/isr.15.1.58

Copyright (C) by Indiana State University All rights reserved. ISSN Online 2577-8188
3. Troup JP. The physiology and biomechanics of competitive swimming. Clin Sports Med. 1999; 18(2):267-285.

https://doi.org/10.1016/S02785919(05)70143-5

4. Kibler WB, Ludewig PM, McClure P, Uhl TL, Sciascia A. Scapular Summit 2009: Introduction. July 16, 2009, Lexington, Kentucky. J Orthop Sports Phys Ther. 2009;39(1 1):A1-A13. https://doi.org/10.2519/iospt.2009.0303

5. Kibler WB, Ludewig PM, McClure PW, Michener LA, Bak K, Sciascia AD. Clinical implications of scapular dyskinesis in shoulder injury: The 2013 consensus statement from the 'Scapular Summit'. $\mathrm{Br} J$ Sports Med. 2013;47(14):877-885.

http://dx.doi.org/10.1136/bjsports-2013$\underline{092425}$

6. Ludewig PM, Cook TM. Alterations in shoulder kinematics and associated muscle activity in people with symptoms of shoulder impingement. Phys Ther. 2000;80(3):276291.

7. McClure P, Greenberg E, Kareha S. Evaluation and management of scapular dysfunction. Sports Med Arthrosc. $2012 ; 20(1): 39-48$.

https://doi.org/10.1097/JSA.0b013e3182 $4716 a 8$

8. Morais N, Cruz J. The pectoralis minor muscle and shoulder movement-related impairments and pain: Rationale, assessment and management. Phys Ther Sport. 2016;17:1-13. https://doi.org/10.1016/i.ptsp.2015.10.00 $\underline{3}$

9. Borstad JD, Ludewig PM. The effect of long versus short pectoralis minor resting length on scapular kinematics in healthy individuals. $J$ Orthop Sports Phys Ther. 2005;35(4):227238.

https://doi.org/10.2519/iospt.2005.35.4.2 $\underline{27}$

10. Muraki T, Aoki $M$, Izumi T, Fujii $M$, Hidaka $E$, Miyamoto $S$. Lengthening of the pectoralis minor muscle during passive shoulder motions and stretching techniques: A cadaveric biomechanical study. Phys Ther. 
2009;89(4):333-341. https://doi.org/10.2522/pti.20080248

11. Lee JH, Cynn HS, Yi CH, Kwon OY, Yoon TL. Predictor variables for forward scapular posture including posterior shoulder tightness. J Bodyw Mov Ther. 2015;19(2):253-260. https://doi.org/10.1016/i.jbmt.2014.04.01 $\underline{0}$

12. Hibberd EE, Oyama S, Spang JT, Prentice W, Myers JB. Effect of a 6-week strengthening program on shoulder and scapular-stabilizer strength and scapular kinematics in division I collegiate swimmers. I Sport Rehabil. 2012;21(3):253-265.

13. Rosa DP, Borstad JD, Pogetti LS, Camargo PR. Effects of a stretching protocol for the pectoralis minor on muscle length, function, and scapular kinematics in individuals with and without shoulder pain. I Hand Ther. 2017;30(1):20-29.

https://doi.org/10.1016/i.jht.2016.06.006

14. Turgut E, Duzgun I, Baltaci G. Stretching Exercises for Subacromial Impingement Syndrome: Effects of 6-Week Program on Shoulder Tightness, Pain and Disability Status. J Sport Rehabil. 2018;27(2):132-137. https://doi.org/10.1123/isr.2016-0182

15. Williams JG, Laudner KG, McLoda T. The acute effects of two passive stretch maneuvers on pectoralis minor length and scapular kinematics among collegiate swimmers. Int $J$ Sports Phys Ther. 2013;8(1):25-33.

16. Laudner KG, Wenig $M$, Selkow NM, Williams $J$, Post E. Forward shoulder posture in collegiate swimmers: A comparative analysis of muscle-energy techniques. I Athl Train. 2015;50(1 1):1133-1139.

https://doi.org/10.4085/1062-605050.11 .07

17. Bron $C$, de Gast A, Dommerholt J, Stegenga $B$, Wensing M, Oostendorp RA. Treatment of myofascial trigger points in patients with chronic shoulder pain: A randomized, controlled trial. BMC Med. 2011;9:8. https://doi.org/10.1186/1741-7015-9-8

18. Jones LH. Spontaneous release by positioning. AAO Journal. 2012;22(1):54-61.

19. Segura-Ortí E, Prades-Vergara $S$, Manzaneda-Piña L, Valero-Martínez R, Polo-
Traverso JA. Trigger point dry needling versus strain-counterstrain technique for upper trapezius myofascial trigger points: A randomised controlled trial. Acupunct Med. 2016;34(3):171-177.

http://dx.doi.org/10.1136/acupmed-2015$\underline{010868}$

20. Jones L, Kusunose R, Goering E. Jones Straincounterstrain. Boise, ID: Jones StrainCounterstrain, Inc; 1995.

21. Speicher TE, Draper DO. Top-10 positionalrelease therapy techniques to break the chain of pain: Part 1. Athletic Therapy Today. 2006; 11 (5):60-62.

22. Speicher TE. Clinical Guide to Positional Release Therapy. Champaigne, IL: Human Kinetics; 2016.

23. Chaitow L. Positional release techniques. 3rd ed. Philadelphia: Churchill Livingstone Elsevier; 2007.

24. D'Ambrogio K, Roth G. Positional release therapy: Assessment and treatment of musculoskeletal dysfunction. St. Louis: Mosby; 1997.

25. Jones L. Strain-counterstrain. Indianapolis: Jones Strain-Counterstrain Inc; 1995.

26. Meseguer A, Fernandez-de-las-Penas C, Navarro-Poza J, Rodriguez-Blanco C, Bosca Gandia J. Immediate effects of the straincounterstrain technique in local pain evoked by tender points in the upper trapezius muscle. Clinical Chiropractic. 2006;9:112118.

https://doi.org/10.1016/i.clch.2006.06.003

27. Dardzinski JA, Ostrov BE, Hamann LS. Myofascial pain unresponsive to standard treatment: Successful use of a strain and counterstrain technique with physical therapy. J Clin Rheumatol. 2000;6(4):169-174. https://doi.org/10.1097/00124743200008000-00001

28. Kelencz CA, Tarini VA, Amorim CF. Trapezius upper portion trigger points treatment purpose in positional release therapy with electromyographic analysis. N Am J Med Sci. $2011 ; 3(10): 451-455$.

https://doi.org/10.4297/naims.2011.3451

29. Wong CK. Strain counterstrain: Current concepts and clinical evidence. Man Ther. 
$2012 ; 17(1): 2-8$.

https://doi.org/10.1016/i.math.2011.10.00 1

30. Wong CK, Abraham T, Karimi $P$, Ow-Wing $C$. Strain counterstrain technique to decrease tender point palpation pain compared to control conditions: A systematic review with meta-analysis. J Bodyw Mov Ther. 2014;18(2):165-173. https://doi.org/10.1016/i.jbmt.2013.09.01 $\underline{0}$

31. Speicher TE, Draper DO. Top-10 positionalrelease therapy techniques to break the chain of pain: Part 2. Athletic Therapy Today. 2006; 11 (6):56-58.

32. Borstad JD. Measurement of pectoralis minor muscle length: Validation and clinical application. J Orthop Sports Phys Ther. 2008;38(4):169-174.

https://doi.org/10.2519/iospt.2008.2723

33. Peterson $D E$, Blankenship KR, Robb JB, et al. Investigation of the validity and reliability of four objective techniques for measuring forward shoulder posture. J Orthop Sports Phys Ther. 1997;25(1):34-42. https://doi.org/10.2519/iospt.1997.25.1.3 4

34. Kibler WB. The role of the scapula in athletic shoulder function. Am J Sports Med.1998;26(2):325-337. https://doi.org/10.1177/0363546598026 0022801

35. Ludewig PM, Reynolds JF. The association of scapular kinematics and glenohumeral joint pathologies. I Orthop Sports Phys Ther.2009;39(2):90-104. https://doi.org/10.2519/iospt.2009.2808

36. Paulson G, Selkow NM, Begalle RL. The effects of a shoulder strengthening program on scapular positioning in collegiate swimmers. J Ath Train. 2018; 6 (53):S42. https://doi.org/10.4085/1062-6050$\underline{53.6 s .51}$ 